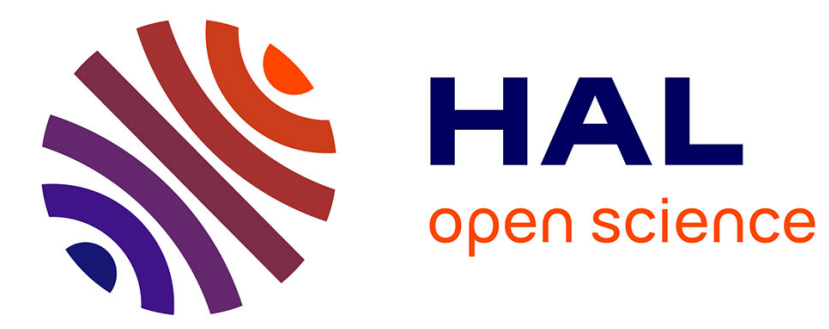

\title{
Potential dry matter and water import rates in the tomato fruit in relationship to fruit size \\ Philippe Bussières
}

\section{To cite this version:}

Philippe Bussières. Potential dry matter and water import rates in the tomato fruit in relationship to fruit size. Annals of Botany, 1993, 72, pp.63-72. hal-02712843

\section{HAL Id: hal-02712843 \\ https://hal.inrae.fr/hal-02712843}

Submitted on 1 Jun 2020

HAL is a multi-disciplinary open access archive for the deposit and dissemination of scientific research documents, whether they are published or not. The documents may come from teaching and research institutions in France or abroad, or from public or private research centers.
L'archive ouverte pluridisciplinaire HAL, est destinée au dépôt et à la diffusion de documents scientifiques de niveau recherche, publiés ou non, émanant des établissements d'enseignement et de recherche français ou étrangers, des laboratoires publics ou privés. 


\title{
Potential Dry Matter and Water Import Rates in the Tomato Fruit in Relationship to Fruit Size
}

\author{
P. BUSSIÈRES \\ Centre de Recherches Agronomiques, INRA, 84143 Montfavet Cedex, France
}

Accepted: 25 January 1993

\begin{abstract}
The tomato fruit was compared to a sphere with a radius $R$. Radial growth rates in the fruit $\left(F_{\mathrm{TW}}\right.$ and $\left.F_{\mathrm{ID}}\right)$ due to water import or to dry matter import, respectively, which are also the water import rate or dry matter import rate per unit surface area of fruit, were calculated from two sets of published results. This data referred to fruits which swelled in such a way that the availability of assimilates had little effect on growth. Two varieties differentiated the two series of results and in one series, three trials were differentiated by the salinity of the nutrient solution.

In all trials, it was found that $F_{\mathrm{IW}}$ and $F_{\mathrm{ID}}$ decreased when $R$ increased. Two phases were observed for $F_{\mathrm{IW}}$ : after a first phase, $F_{\mathrm{IW}}$ decreased more quickly and almost linearly when $R$ increased. $F_{\mathrm{ID}}$ was constant or decreased with respect to $R$. Except at the beginning of growth at the greatest salinity, there were clearly linear regressions between $F_{\mathrm{IW}}$ and $F_{\mathrm{ID}}$ such as $F_{\mathrm{ID}}=a F_{\mathrm{IW}}-b$; where $b$ was lower with higher salinity. The changes of the concentration of imported dry matter $\left(F_{\mathrm{ID}} / F_{\mathrm{IW}}\right)$ were examined in terms of $R$ and $F_{\mathrm{IW}} / R$. The mechanisms controlling the changes in $F_{\mathrm{IW}}$ and $F_{\mathrm{ID}}$ were discussed. The results suggested fruit radius was an important parameter of these mechanisms. Thus, water import rate and dry matter import rate could each be considered to be the product of two factors: fruit surface area, which is directly dependent on fruit radius, and water import rate or dry matter import rate per unit of fruit surface area.
\end{abstract}

Key words: Dry matter, fruit growth, logistic model, sink size, tomato, water transfer.

\section{INTRODUCTION}

The growth of a fruit is without doubt a phenomenon which results from a large number of the plant mechanisms. However, fruit growth is also an important factor of the plant functioning when the fruit is a priority sink for assimilates, as seems to be the case in the tomato (Hurd, Gay and Mountifield, 1979). Therefore, it is essential to quantify the growth kinetics of fruit, and the tomato is a particularly interesting example when growth rate does not seem to be restricted by assimilate availability (i.e. "potential growth'). Quantification would be useful to control growth of the first tomato fruits and promote leaf growth (Dumas and Bussières, 1992) or to control fruit dry matter content which is now an important aspect for the selling price of tomato fruit.

It is standard practice to model organ growth rate according to a logistic law:

$$
\mathrm{d} M / \mathrm{d} t=c M\left(M_{\text {TIN }}-M\right)
$$

where $M_{F, N}$ is the final value of $M$, organ mass, and $c$ is a constant. This model is expressed by a parabolic curve. As suggested by Robertson (1908), this law reflects the rate of an autocatalytic monomolecular reaction whose rate is proportional to reagent and product concentration. Gustafson (1926) suggested that this model could be applied to tomato fruit growth.

Nevertheless, this model is very global. It does not explain the different components, i.e. water and dry matter imports, or losses by respiration and transpiration. Respiration and transpiration of tomato fruit are correlated with dry matter accunulation rate in tomato fruit or fruit mass. Consequently, the main problem concerns the import rates of water and dry matter. Ho, Grange and Picken (1987) estimated these rates, and the dry matter concentration of imported sap, and how they were affected by the nutrient solution salinity. They studied these changes as a function of time: the rates increase, then decrease according to a bell shaped curve which is more or less distorted. The explanation of these import rates remains an essential point.

It is also generally thought that fruit growth depends on hormonal substances, particularly IAA, in tomato fruit (Ho, Sjut and Hoad, 1983). These substances are secreted by the seeds of fleshy fruits and would contribute to tissue vascularization (Jahn, 1978). This would explain what has often been observed in the tomato (Dempsey and Boyton, 1965; Maisonneuve and Philouze, 1982; Philouze, 1983), and in other fruits, particularly kiwi fruit (Lai, Wooley and Lawes, 1990), that final fruit weight is positively correlated to the number of seeds.

A priori, the increase in vascularization during swelling could explain the growth rates when they increase. In respect to the decrease in rate, Gustafson (1927) suggested that the vascular system could become 'inadequate' at large distances when fruit size increases.

By studying the rate of carbon import into tomatoes of varying sizes and at varying temperatures, Walker and Thornley (1977) found that the sucrose flux $Q$ entering the fruit is proportional to the sucrose concentration gradient between the fruit and the remainder of plant. However, 
these authors did not find any clear relationship between the flux value $Q$ divided by an estimate of transfer area at the fruit pedicel level and the preceding sucrose gradient. The authors suggested the possibility of a change in transfer resistance due to a change in the length of transfer pathways. Lee, Dixon and Johnson (1989) and Lee (1990) suggested that the growth rate could be controlled by a water potential gradient generated by transpiration rate. This gradient could be dependent on the length of transfer pathways. Moreover, Walker and Ho (1977b) suggested that the sucrose import in tomato could be controlled by the sucrose hydrolysis rate.

In many varieties, tomato fruit is a perceptibly spherical fruit. Thus, in a variety with spherical fruit, a priori, it is reasonable to assume that the resistances in the transfer pathways would be simply linked to the radial size of fruit. On this hypothesis, and on the hypothesis of control of import rates by transfer rates, it seemed interesting to study the import rates through their radial component which is the sum of growth rates along the fruit radius. Thus, in this work, the radial growth rates due to water or dry matter import rates were considered and examined as a function of fruit radius. For this purpose, we created a model involving fruit geometry and used it to reinterpret published data sets.

\section{MATERIALS AND METHODS}

The hypothesis and the model of water and dry matter accumulation and import rates

At a time $t$, the rate of change of fruit mass, $M_{\mathrm{F}}$, was the sum of water accumulation rate $\left(\mathrm{d} M_{\mathrm{Aw}} / \mathrm{d} t\right)$ and $\mathrm{dry}$ matter accumulation rate $\left(\mathrm{d} M_{\mathrm{AD}} / \mathrm{d} t\right)$ :

$$
\mathrm{d} M_{\mathrm{F}} / \mathrm{d} t=\mathrm{d} M_{\mathrm{AW}} / \mathrm{d} t+\mathrm{d} M_{\mathrm{AD}} / \mathrm{d} t
$$

The water accumulation rate was the difference between the sum of the water import (import $=$ net influx) rate in the fruit $\left(\mathrm{d} . M_{\mathrm{IW}} / \mathrm{d} t\right)$ and the accumulation rate of the water produced from the dry matter broken down by respiration $\left(\mathrm{d} M_{\mathrm{RW}} / \mathrm{d} t\right)$, less the rate of water loss through transpiration $\left(\mathrm{d} M_{\mathrm{I} w} / \mathrm{d} t\right)$ :

$$
\mathrm{d} M_{\mathrm{AW}} / \mathrm{d} t=\mathrm{d} M_{\text {IW }} / \mathrm{d} t+\mathrm{d} M_{\mathrm{I} w} / \mathrm{d} t-\mathrm{d} M_{\mathrm{TW}} / \mathrm{d} t
$$

When the rate of dry matter loss through respiration was $\mathrm{d} M_{\mathrm{RD}} / \mathrm{d} t$, the rate $\mathrm{d} M_{\mathrm{Rw}} / \mathrm{d} t$ was estimated as:

$$
\mathrm{d} M_{\mathrm{RW}} / \mathrm{d} t=\left(\mathrm{d} M_{\mathrm{RD}} / \mathrm{d} t\right) C W
$$

where it was supposed that $C W$ was equal to 0.6 (product of the fruit dry matter carbon content, $40 \%$, and of the ratio of a water molecule mass to a carbon atom mass, 18/12). According to Walker and Ho (1977a) and Ho et al. (1987), the rate of dry matter loss through respiration was:

$$
\mathrm{d} M_{\mathrm{RD}} / \mathrm{d} t=0.008 M_{\mathrm{AD}}=0.008 M_{\mathrm{F}} T_{\mathrm{ADF}}
$$

$M_{\mathrm{AD}}$ being the dry matter mass accumulated in the fruit and $T_{\mathrm{ADF}}$ the fruit dry matter content.

According to these authors, transpiration rate was:

$$
\mathrm{d} M_{\mathrm{TW}} / \mathrm{d} t=0.012 M_{\mathrm{F}}
$$

An increase in the volume of water in the fruit $\mathrm{d} V_{\mathrm{IW}}$ was

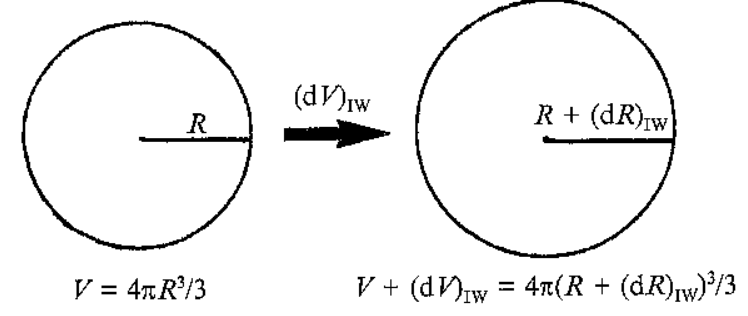

FIG. 1. Relation between the volume and radius of a sphere after an increase $(\mathrm{d} V)_{\mathrm{IW}}$ in volume $V$ corresponding to an increase $(\mathrm{d} R)_{\mathrm{IW}}$ in radius $R$.

associated with the water mass $\mathrm{d} M_{\mathrm{IW}}$ imported during $\mathrm{d} t$, so that:

$$
\mathrm{d} M_{\text {IW }} / \mathrm{d} t=\sigma_{\mathrm{W}} \mathrm{d} V_{\mathrm{IW}} / \mathrm{d} t
$$

where $\sigma_{\mathrm{w}}$ was the density of water (equal to $1 \mathrm{~g} \mathrm{~cm}^{-3}$ at $4{ }^{\circ} \mathrm{C}$ ).

Approximating the fruit to a sphere with radius $R$ (Fig. 1), an increase in fruit radius $(\mathrm{d} R)_{\text {IW }}$ due to water import was associated with the water volume increase $\mathrm{d} V_{\mathrm{IW}}$, so that:

$$
\mathrm{d} V_{\mathrm{IW}}=4 \pi\left[R+(\mathrm{d} R)_{\mathrm{IW}}\right]^{3} / 3-4 \pi R^{3} / 3
$$

If $(\mathrm{d} R)_{\mathrm{IW}}$ is small compared with $R$, it follows, approximately:

$$
\mathrm{d} M_{\mathrm{rW}} / \mathrm{d} t=4 \pi \sigma_{\mathrm{w}} R^{2}(\mathrm{~d} R / \mathrm{d} t)_{\mathrm{IW}}
$$

A water mass imported per unit time per unit surface area of tomato, which was also a radial growth rate $\left(F_{\text {IW }}\right)$ due to water importation, corresponded to this rate $\mathrm{d} M_{\mathrm{IW}} / \mathrm{d} t$, such as:

$$
F_{\mathrm{IW}}=\left(\mathrm{d} M_{\mathrm{IW}} / \mathrm{d} t\right) / 4 \pi R^{2}=\sigma_{\mathrm{W}}(\mathrm{d} R / \mathrm{d} t)_{\mathrm{WW}}
$$

The dry matter accumulation rate was the difference between the rate of dry matter import into the fruit $\left(\mathrm{d} M_{\mathrm{ID}} / \mathrm{d} t\right)$ and the rate of the losses through respiration:

$$
\mathrm{d} M_{\mathrm{AD}} / \mathrm{d} t=\mathrm{d} M_{\mathrm{ID}} / \mathrm{d} t-\mathrm{d} M_{\mathrm{RD}} / \mathrm{d} t
$$

As in the case of water import rate, $\mathrm{d} M_{\mathrm{ID}} / \mathrm{d} t$ was:

$$
\mathrm{d} M_{\mathrm{ID}} / \mathrm{d} t=4 \pi \sigma_{\mathrm{ID}} R^{2}(\mathrm{~d} R / \mathrm{d} t)_{\mathrm{ID}}
$$

where $(\mathrm{d} R / \mathrm{d} t)_{\mathrm{ID}}$ was the rate of increase in the fruit radius due to dry matter import, and $\sigma_{\text {ID }}$ was the density of dry matter. A dry matter mass imported per unit time per unit surface area of tomato, which was also a radial growth rate $\left(F_{\text {ID }}\right)$ due to dry matter importation, corresponded to this rate $\mathrm{d} M_{\mathrm{ID}} / \mathrm{d} t$, such as:

$$
F_{\mathrm{ID}}=\left(\mathrm{d} M_{\mathrm{ID}} / \mathrm{d} t\right) / 4 \pi R^{2}=\sigma_{\mathrm{ID}}(\mathrm{d} R / \mathrm{d} t)_{\mathrm{ID}}
$$

Obviously the ratio $F_{\mathrm{ID}} / F_{\mathrm{IW}}$ was equal to the ratio $\left(\mathrm{d} M_{\mathrm{ID}} / \mathrm{d} t\right) /\left(\mathrm{d} M_{\mathrm{IW}} / \mathrm{d} t\right)$, which is the dry matter concentration in imported sap.

\section{Bibliographic data used}

We used two sets of published results. One, termed $\mathrm{S}$, was drawn from the work by Ho et al. (1987) and the other, 
TABLE 1. Data on the tomato fruit growth from $\mathrm{Ho}$ et al. (1987)

\begin{tabular}{|c|c|c|c|c|}
\hline $\begin{array}{l}\text { Days } \\
\text { after pollination }\end{array}$ & $\begin{array}{c}\mathrm{d} M_{\mathrm{ID}} / \mathrm{d} t \\
\left(\mathrm{~g} \mathrm{~d}^{-1}\right)\end{array}$ & $\begin{array}{l}\mathrm{d} M_{\mathrm{rWW}} / \mathrm{d} t \\
\left(\mathrm{~g} \mathrm{~d}^{-1}\right)\end{array}$ & $\begin{array}{l}\mathrm{d} M_{\mathrm{IXw}} / \mathrm{d} t \\
\quad\left(\mathrm{~g} \mathrm{\textrm {d } ^ { - 1 }}\right)\end{array}$ & $\begin{array}{c}\mathrm{d} M_{\mathrm{TW}} / \mathrm{d} t \\
\left(\mathrm{~g} \mathrm{~d}^{-1}\right)\end{array}$ \\
\hline \multicolumn{5}{|c|}{ Salinity $=2 \mathrm{mS} \mathrm{cm}^{-1}$} \\
\hline 14 & 0.138 & $2 \cdot 30$ & 0.34 & 0.20 \\
\hline 21 & 0.186 & $3 \cdot 10$ & 0.39 & 0.44 \\
\hline 28 & 0.158 & $3 \cdot 20$ & 0.28 & 0.66 \\
\hline 35 & 0.098 & $2 \cdot 62$ & 0.24 & 0.82 \\
\hline 42 & 0.060 & 2.00 & 0.09 & 0.91 \\
\hline 49 & 0.042 & 1.42 & 0.03 & 0.97 \\
\hline \multicolumn{5}{|c|}{ Salinity $=12 \mathrm{mS} \mathrm{cm}^{-1}$} \\
\hline 14 & $0 \cdot 180$ & $2 \cdot 40$ & 0.22 & $0 \cdot 20$ \\
\hline 21 & $0 \cdot 215$ & $2 \cdot 90$ & 0.27 & 0.44 \\
\hline 28 & 0.160 & $2 \cdot 30$ & 0.16 & 0.59 \\
\hline 35 & 0.080 & 1.42 & 0.05 & 0.66 \\
\hline 42 & 0.050 & 1.00 & 0.02 & 0.69 \\
\hline 49 & 0.035 & 0.80 & 0.01 & 0.70 \\
\hline \multicolumn{5}{|c|}{ Salinity $=17 \mathrm{mS} \mathrm{cm}^{-1}$} \\
\hline 14 & $0 \cdot 180$ & 1.45 & $0 \cdot 12$ & $0 \cdot 15$ \\
\hline 21 & $0 \cdot 160$ & 1.80 & 0.08 & 0.29 \\
\hline 28 & $0 \cdot 130$ & 1.70 & 0.07 & 0.41 \\
\hline 35 & $0 \cdot 100$ & 1.35 & 0.05 & 0.48 \\
\hline 42 & 0.080 & 1.02 & 0.04 & 0.53 \\
\hline 49 & 0.062 & 0.80 & 0.02 & 0.56 \\
\hline
\end{tabular}

$\left(\mathrm{d} M_{\mathrm{ID}} / \mathrm{d} t=\right.$ dry matter import rate in fruit; $\mathrm{d} M_{\mathrm{IW}} / \mathrm{d} t=$ water import rate in fruit; $\mathrm{d} M_{\mathrm{Lx}} / \mathrm{d} t=$ xylem water import rate in fruit; $\mathrm{d} M_{\mathrm{TW}} / \mathrm{d} t=$ transpiration rate of fruit).

TABLE 2. Data on the tomato fruit growth from Ho et al. (1983), Ho and Hewitt (1986) and from Gustafson (1926)

\begin{tabular}{|c|c|c|c|}
\hline $\begin{array}{l}\text { Days } \\
\text { after pollination }\end{array}$ & $\begin{array}{c}\mathrm{d} M_{\mathrm{AD}} / \mathrm{d} t \\
\left(\mathrm{~g} \mathrm{~d}^{-1}\right)\end{array}$ & $\begin{array}{c}M_{\mathrm{AD}} \\
(\mathrm{g})\end{array}$ & $\begin{array}{l}T_{\mathrm{ADF}} \\
(\%)\end{array}$ \\
\hline 7 & 0.030 & 0.03 & $11 \cdot 70$ \\
\hline 10 & 0.080 & $0 \cdot 20$ & $8 \cdot 52$ \\
\hline 13 & $0 \cdot 140$ & 0.50 & 6.82 \\
\hline 16 & 0.245 & $1 \cdot 00$ & $6 \cdot 38$ \\
\hline 19 & 0.335 & 1.90 & 6.27 \\
\hline $22 \cdot 5$ & 0.375 & $3 \cdot 20$ & $6 \cdot 15$ \\
\hline $25 \cdot 5$ & 0.330 & $4 \cdot 20$ & 604 \\
\hline 29 & 0.275 & $5 \cdot 1.5$ & 5.92 \\
\hline 31.5 & 0.230 & $5 \cdot 60$ & 5.83 \\
\hline 34.5 & 0.190 & $6 \cdot 35$ & 5.73 \\
\hline 37 & $0 \cdot 160$ & 6.90 & $5 \cdot 64$ \\
\hline 40 & 0.130 & $7 \cdot 30$ & $5 \cdot 53$ \\
\hline 43 & $0 \cdot 110$ & 7.70 & $5 \cdot 42$ \\
\hline 46 & 0.090 & 8.00 & $5 \cdot 32$ \\
\hline 53 & $0 \cdot 050$ & $8 \cdot 50$ & 5.07 \\
\hline
\end{tabular}

$M_{\mathrm{AD}}=$ fruit dry matter mass; $\mathrm{d} M_{\mathrm{AD}} / \mathrm{d} t=$ dry matter accumulation rate in fruit; $T_{\mathrm{ADF}}=$ fruit dry matter content.

termed $\mathrm{H}$, was drawn from the works by Ho et al. (1983) and Ho and Hewitt (1986). In these works, the authors studied the growth of the tomato fruit in the proximal position on the fruit cluster. Given this position and the experimental conditions described by the authors, it can be supposed that assimilate availability did not limit fruit growth.

Series $S$ data. Three experiments were differentiated by the nutrient solution salinity $\left(2,12\right.$ and $\left.17 \mathrm{mS} \mathrm{cm}^{-1}\right)$. The maximum fresh fruit mass at $2 \mathrm{mS} \mathrm{cm}^{-1}$ was approximately $80 \mathrm{~g}$. The authors estimated the rates of dry matter and water import from the changes in accumulated dry matter and water mass and from estimates of losses through transpiration and respiration according to eqns (5) and (6). Moreover, the authors estimated the rate of xylem water import from fruit calcium content. The values of these rates deduced from authors' curves are given in Table 1. Fruits of the tomato variety used in these trials were estimated to be 'spheric' by Ehret and Ho (1986).

Series $H$ data. From the conditions described by the authors, where the plants were grown in pots with a mixture of sand and peat, the salinity was probably about $2 \mathrm{mS} \mathrm{cm}^{-1}$. The variety, which was different from the variety used in series $S$, is considered to have perceptible round fruits (Philouze, pers. comm.). Between 6 and $8 \mathrm{~d}$ after pollination, the fresh fruit mass was $0.256 \mathrm{~g}$ based on $30 \mathrm{mg}$ of dry matter with a dry matter content of $11.7 \%$. Growth continued for $55 \mathrm{~d}$, when dry matter mass was $8.6 \mathrm{~g}$ and fresh fruit mass was about $170 \mathrm{~g}$. The dry matter content of fruit at $55 \mathrm{~d}$ was therefore approximately equal to $5 \%$. The other data on accumulated dry matter mass and dry matter accumulation rate, shown in Table 2 , were deduced from the authors' curves. The values of dry matter content during growth (Table 2) were deduced from one of the typical curves of variation in dry matter content which was indicated by Gustafson (1926). This curve includes the two extreme values quoted above $(11.7$ and $5 \%)$.

\section{Measuring density $\left(\sigma_{F}\right)$ of fruits of different weights}

$\sigma_{\mathrm{F}}$ was estimated by measuring the volume of water displaced by tomato fruits of different weights. These fruits (cv. Promo) were sampled at the same time from a field crop and the heaviest fruits were beginning to turn red. The pollination date was not known, but it was clear that there was a correlation between fruit weight and pollination date.

\section{Estimates from published data}

Series $S$ data. At the different dates, fruit weight was deduced from transpiration rate (Table 1) with the eqn (6) that the authors used to calculate the values of transpiration rate from the fruit weight values. $R$ was calculated as:

$$
R=\left[3 M_{\mathrm{r}} /\left(4 \pi \sigma_{\mathrm{F}}\right)\right]^{1 / 3}
$$

assuming $\sigma_{\mathrm{F}}$ was $0.95 \mathrm{~g} \mathrm{~cm}^{-3}$.

The $F_{\mathrm{ID}}$ and $F_{\mathrm{IW}}$ rates, as well as the radial growth rate due to xylem water import, termed $F_{\mathrm{IXw}}$, were calculated based on the import rates (Table 1) and according to eqns (9), (10), (12) and (13), as:

$$
\begin{aligned}
F_{\mathrm{ID}} & =\left(\mathrm{d} M_{\mathrm{ID}} / \mathrm{d} t\right) /\left(4 \pi R^{2}\right) \\
F_{\mathrm{IW}} & =\left(\mathrm{d} M_{\mathrm{IW}} / \mathrm{d} t\right) /\left(4 \pi R^{2}\right) \\
F_{\mathrm{IXW}} & =\left(\mathrm{d} M_{\mathrm{IXW}} / \mathrm{d} t\right) /\left(4 \pi R^{2}\right) .
\end{aligned}
$$




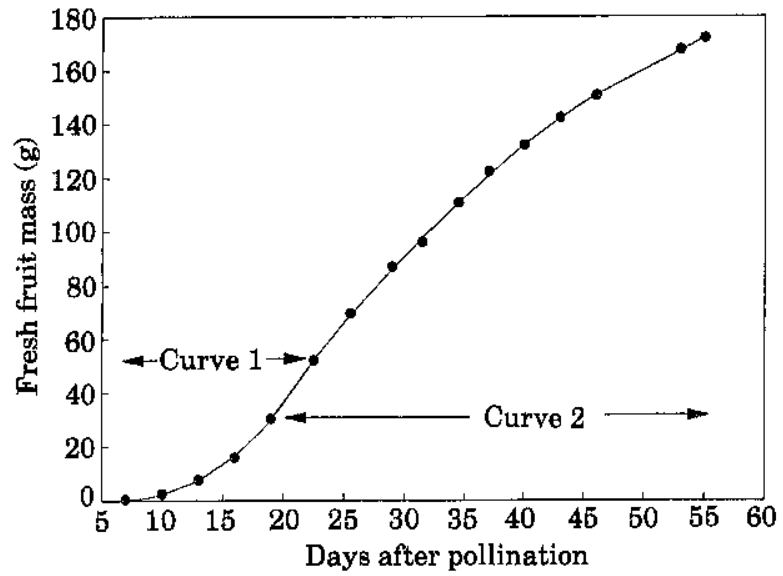

FIG, 2. Fresh fruit mass $\left(M_{\mathrm{F}}\right)$ in relation to time $(t)$ from the experiment of Ho et al. (1983). Values which were taken from the data in Table $2(0)$. Linear adjustment to the third order polynomial in relation to $t$ (curve 1), linear adjustment to the fifth order polynomial in relation to $t$ (curve 2).

Series $H$ data. The $F_{\mathrm{IW}}$ rate was calculated from eqns (3)-(10) which yielded:

$F_{\mathrm{IW}}=\left(\mathrm{d} M_{\mathrm{F}} / \mathrm{d} t-\mathrm{d} M_{\mathrm{AD}} / \mathrm{d} t-0.0048 M_{\mathrm{AD}}+0.012 M_{\mathrm{F}}\right) /$

$M_{\mathrm{T}}$ was obtained from $M_{\mathrm{AD}}$ and $T_{\mathrm{ADF}}$ (Table 2). The values of $\mathrm{d} M_{\mathrm{F}} / \mathrm{d} t$ at different dates shown in Table 2 were estimated as follows. For $7 \leqslant t \leqslant 22 \cdot 5$, the cubic regression (Fig. 2, curve 1) of $M_{\mathrm{F}}$ on time $t$ was calculated with the constraint of a zero deviation at day 7 :

$M_{\mathrm{F}}=0 \cdot 256+0 \cdot 1520(t-7)+0 \cdot 1453(t-7)^{2}+0 \cdot 0039(t-7)^{3}$

$\left(r^{2}=0.898\right.$ and residual s.e. $\left.=0.473 \mathrm{~g}\right)$.

For $t \geqslant 19$, the fifth order polynomial regression (Fig. 2, curve 2) of $M_{\mathrm{F}}$ on time $t$ was calculated:

$$
\begin{aligned}
M_{\mathrm{F}}= & -324.392+41.1219 t-1.9659 t^{2}+0 \cdot 0540 t^{3} \\
& -\left(7468 \times 10^{-7} t^{4}\right)+\left(4038 \times 10^{-9} t^{5}\right)
\end{aligned}
$$

$\left(r^{2}=0.999\right.$ and residual s.e. $\left.=1.04 \mathrm{~g}\right)$. The derivative of eqn (20) is positive for the all centesimal values of $t$ between 15 and $55 \mathrm{~d}$; thus eqn $(20)$ probably increases throughout this range. When $t$ was equal to $19 \mathrm{~d}$ or lower, $\mathrm{d} M_{\mathrm{F}} / \mathrm{d} t$ was calculated using eqn (19), and when $t$ was equal to $22.5 \mathrm{~d}$ or higher, eqn (20) was used. $R$ was given by eqn (14), $\sigma_{\mathrm{F}}$ was $0.95 \mathrm{~g} \mathrm{~cm}^{-3}$ and the $F_{\text {ID }}$ rate was found from eqns (3)-(13):

$$
F_{\mathrm{ID}}=\left(\mathrm{d} M_{\mathrm{AD}} / \mathrm{d} t+0.008 M_{F} T_{\mathrm{ADF}}\right) /\left(4 \pi R^{2}\right)
$$

Error estimation. The error of values of $F_{\mathrm{IW}}, F_{\mathrm{ID}}$ and $F_{\mathrm{IXW}}$, labelled here simply $F$, relative to $\sigma_{F}$, was calculated as follows. According to equs (14)-(17), $F$ was related to $\sigma_{\mathrm{F}}$ by:

$$
F=k \sigma_{\mathrm{F}}{ }^{2 / 3}
$$

Thus an error $\mathrm{d} \sigma_{\mathrm{F}}$ caused an error $\mathrm{d} F$ such as:

$$
\mathrm{d} F / \mathrm{d} \sigma_{\mathrm{F}}=\left(2 k \sigma_{\mathrm{F}}^{-1 / 3}\right) / 3
$$

or:

$$
\mathrm{d} F=0.67 k \sigma_{\mathrm{F}}^{-1 / 3} \mathrm{~d} \sigma_{\mathrm{F}}=0.67 k \sigma_{\mathrm{F}}{ }^{2 / 3} \mathrm{~d} \sigma_{\mathrm{F}} / \sigma_{\mathrm{F}}
$$

and a relative error on $F$ such that:

$$
\mathrm{d} F / F=0.67 \mathrm{~d} \sigma_{\mathrm{F}} / \sigma_{\mathrm{F}}
$$

\section{RESULTS}

Measurements of fruit density $\left(\sigma_{F}\right)$

$\sigma_{F}$ varied $\pm 2 \%$, and was often between 0.94 and $0.96 \mathrm{~g} \mathrm{~cm}^{-3}$ (Fig. 3); it decreased and then increased with the fruit weight according to two regressions dependent on the ratio $(x)$ between fruit weight to final fruit weight:

$$
\text { for } x \leqslant 0 \cdot 2: \sigma_{\mathrm{F}}=0.9692-0.2067 x \quad(r=0.96, P<0.01)
$$

for $0.15 \leqslant x \leqslant 1: \sigma_{\mathrm{F}}=0.9286+0.0398 x$

$$
(r=0.94, P<0.01)
$$

The rate of radial growth due to water import $\left(\mathrm{F}_{I W}\right)$ in relationship to fruit radius (Fig. 4)

$F_{\text {TW }}$ decreased as the fruit radius increased. In trial $\mathrm{H}$, it was fairly clear that there were two phases. In the second phase, $F_{\mathrm{IW}}$ decreased more rapidly and linearly with $R$. In series $\mathrm{S}$, the data, which varied less than in $\mathrm{H}$, made it possible to point out the existence of two phases with a perceptible linear decrease with $R$ in the second phase. Also in series $\mathrm{S}$, the second phase occurred at a much lower radius when the salinity was higher. $F_{\mathrm{IW}}$ was almost always much lower when salinity was higher and was greater in series $\mathrm{H}$. The slopes showed no consistent variation with salinity.

The rate of radial growth due to water import $\left(\mathrm{F}_{I X W W}\right)$ in relationship to fruit radius (Fig. 5)

The radial growth rate $\left(F_{\text {IXw }}\right)$ due to water import through the xylem decreased when radius increased. There were not two such clear phases as for $F_{\mathrm{IW}}$. When $R$ was small, the effect of salinity was greater than for $F_{\mathrm{IW}}$.

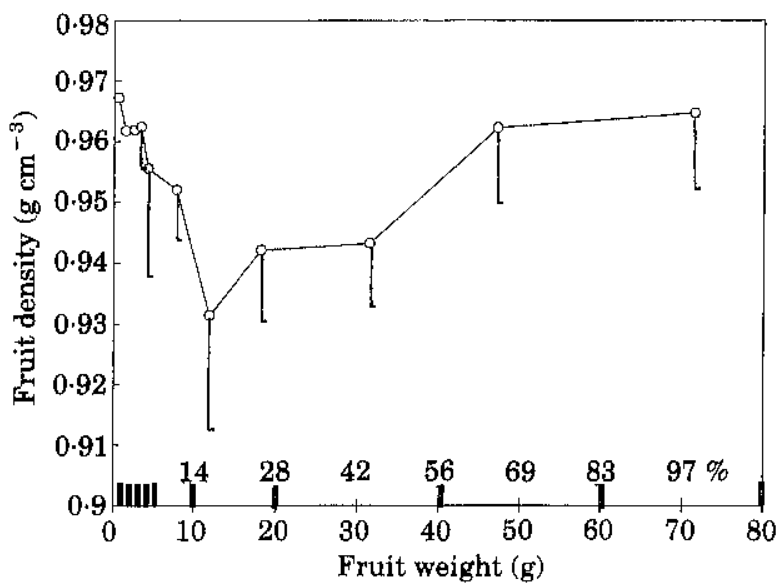

Fig, 3. Density $\left(\sigma_{F}\right)$ of tomato fruits in relation to their weight. The fruits were sampled at the same date from a field crop; in the three lowest classes, the measurements were made on various fiuits at the same time, 27 fruits altogether; some of the fruits weighing over $60 \mathrm{~g}$ were red. Mean per class of weight $(O)$; vertical lines indicate standarddeviation in a class; class limits are marked by heavy lines on the abscissa. 


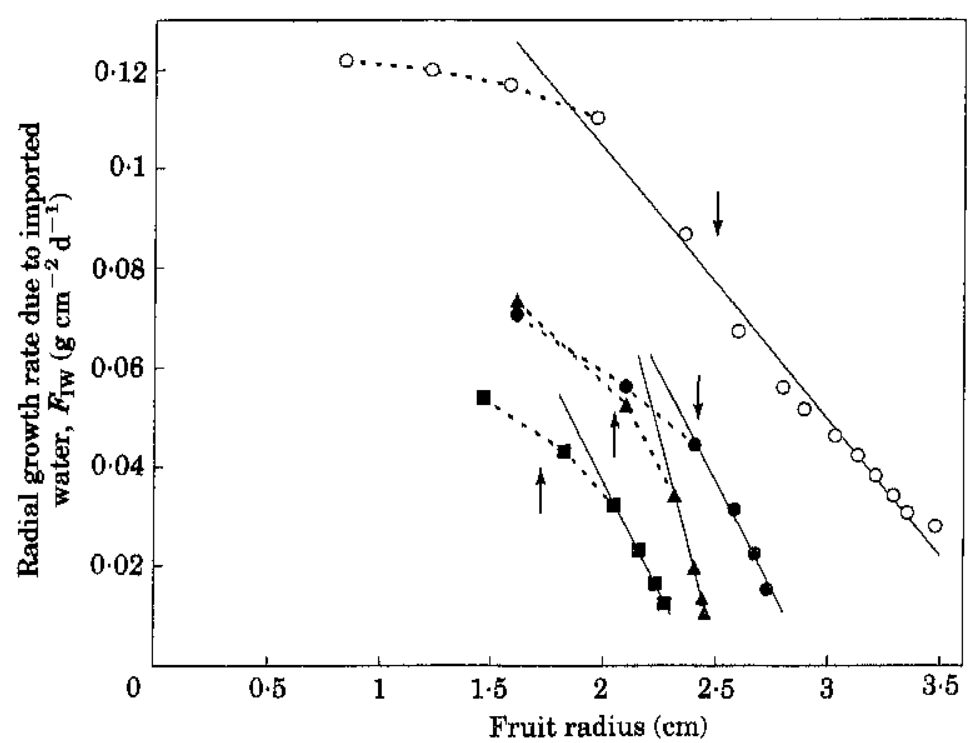

FIG. 4. Change in the fruit radial growth rate due to water import $\left(F_{\mathrm{rW}}\right)$ in relation to radius $(R)$. The plotted regressions were calculated without the two first points in each trial in series $S$ and without the three first points in trial $H$. The vertical arrows show approximately the time at which the water import rate into fruit was maximum.

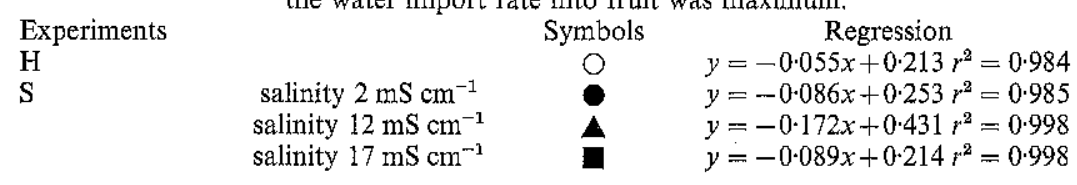

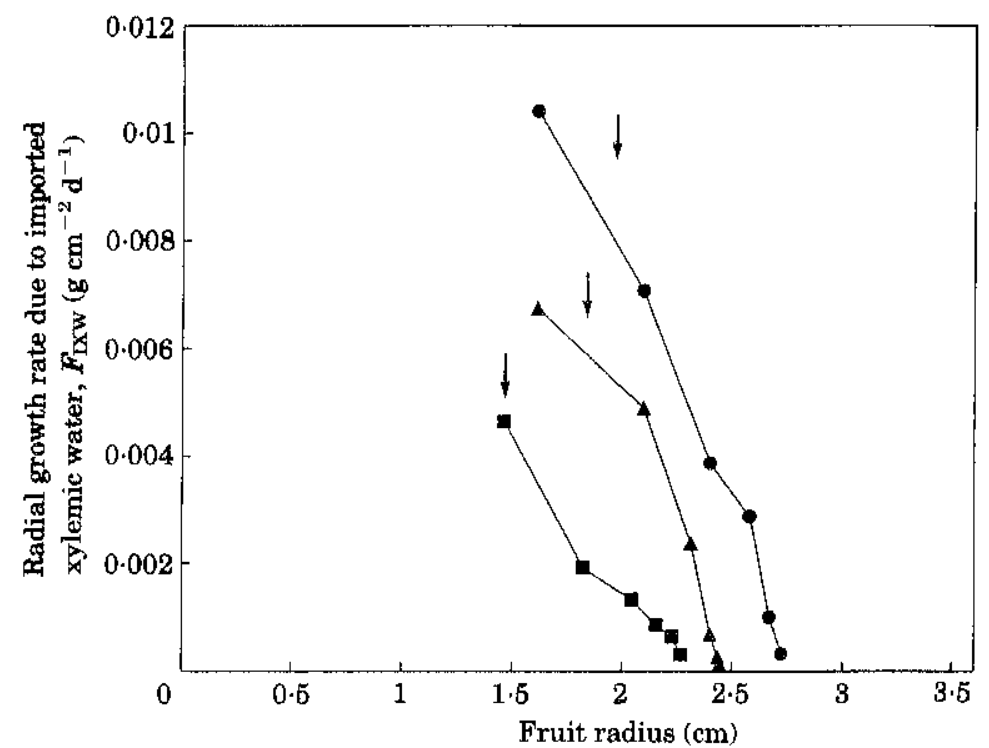

FrG. 5. Change in the fruit radial growth rate due to the xylem water import $\left(F_{\mathrm{IXW}}\right)$ in relation to radius $(R)$. Trials $\mathrm{S}$ at $2(\mathbf{S}), 12(\mathbf{A})$ or 17 $\mathrm{mS} \mathrm{cm}$. The vertical arrows show approximately the time at which the xylem water import rate into fruit was maximum.

The rate of radial growth due to dry matter import $\left(\mathrm{F}_{I D}\right)$ in relationship to radius (Fig. 6)

$F_{\text {ID }}$ decreased when the fruit radius increased. In series $\mathrm{S}$, when $R$ was about $15 \mathrm{~mm}, F_{\mathrm{ID}}$ was much greater when salinity was greater. $F_{\text {ID }}$ was higher in trial $\mathrm{H}$. At low values of $R$ in series $\mathrm{S}$, the slope was much steeper when salinity was greater; and in trial $\mathrm{H}$, the slope value was nearly the same as in series $\mathrm{S}$ at the lowest salinity. In series $\mathrm{S}$ at the greatest salinity, it was noticeable that the decrease was linear. In the other trials, a second phase occurred when the radius increased above about $23 \mathrm{~mm}$ and was characterized by a more rapid linear decrease, except at the end of trial $\mathrm{H}$. In the second phase, the slope was similar in trial $\mathrm{H}$ and trial $\mathrm{S}$ at the lowest salinity and was steeper in the trial at average salinity. 


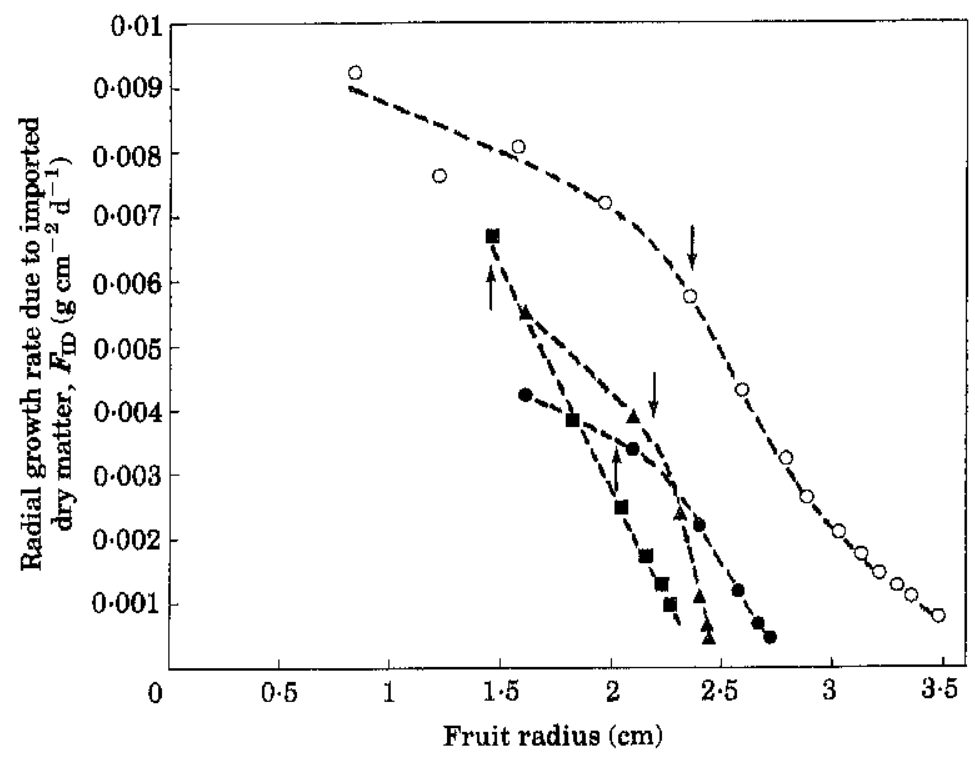

Frg. 6. Change in the fruit radial growth rate due to dry matter import $\left(F_{\mathrm{ID}}\right)$ in relation to radius $(R)$. Trial $\mathrm{H}(\mathrm{O})$, trials $\mathrm{S}$ at $2(\mathbf{O}), 12(\mathbf{A})$ or

$17(\boldsymbol{D}) \mathrm{mS} \mathrm{cm}^{-1}$. The vertical arrows show approximately the time at which the dry matter import rate into fruit was maximum.

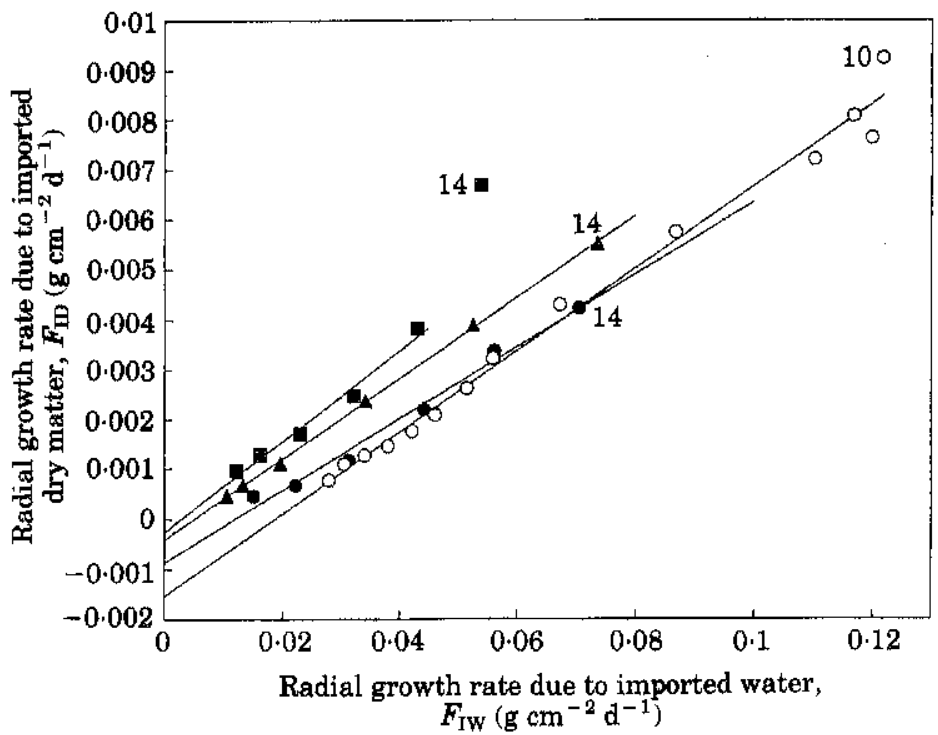

FIG. 7. Fruit radial growth rate due to dry matter import $\left(F_{\mathrm{IDD}}\right)$ in relation to the fruit radial growth rate due to imported water $\left(F_{\text {IW }}\right)$. The numbers show the points of the first dates of observations during fruit swelling (days numbered after pollination). The coefficients of regressions $F_{\mathrm{ID}}=a F_{\mathrm{IW}}-b$ and the $r^{2}$ values were:

\begin{tabular}{|c|c|c|c|c|c|}
\hline Experiments & Symbols & $a$ & $\begin{array}{c}b \times 10^{5} \\
\left(\mathrm{~g} \mathrm{~cm}^{-2} \mathrm{~d}^{-1} \times 10^{-5}\right)\end{array}$ & $r^{2}$ & $\begin{array}{c}b / a \\
\left(\mathrm{~g} \mathrm{~cm}^{-2} \mathrm{~d}^{-1}\right)\end{array}$ \\
\hline $\mathrm{H}$ & 0 & 0.082 & 155 & 0.988 & 0.019 \\
\hline \multicolumn{6}{|l|}{$\mathrm{S}$ at salinity: } \\
\hline $2 \mathrm{mS} \mathrm{cm}^{-1}$ & - & 0.072 & 88 & 0.987 & $0 \cdot 012$ \\
\hline $12 \mathrm{mS} \mathrm{cm}^{-1}$ & 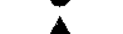 & 0.081 & 42 & 0.999 & 0.005 \\
\hline $\begin{array}{l}17 \mathrm{mS} \mathrm{cm}^{-1} \text { (in } \\
\text { this trial, day } 14\end{array}$ & $=$ & $0 \cdot 091$ & 27 & 0.981 & 0.003 \\
\hline
\end{tabular}

Relationship between radial growth rate due to water import $\left(\mathrm{F}_{I W}\right)$ and radial growth rate due to dry matter import $\left(\mathrm{F}_{I D}\right),($ Fig. 7)

Except for the first value in the trial at the greatest salinity, linear regressions were found between $F_{\mathrm{ID}}$ and $F_{1 \mathrm{~W}}$ :

$$
F_{1 \mathrm{D}}=a F_{\mathrm{IW}}-b
$$

$b$ decreased with salinity. The correlation between $F_{\mathrm{ID}}$ and $F_{\mathrm{rw}}$ was much higher than the correlation between the rate 


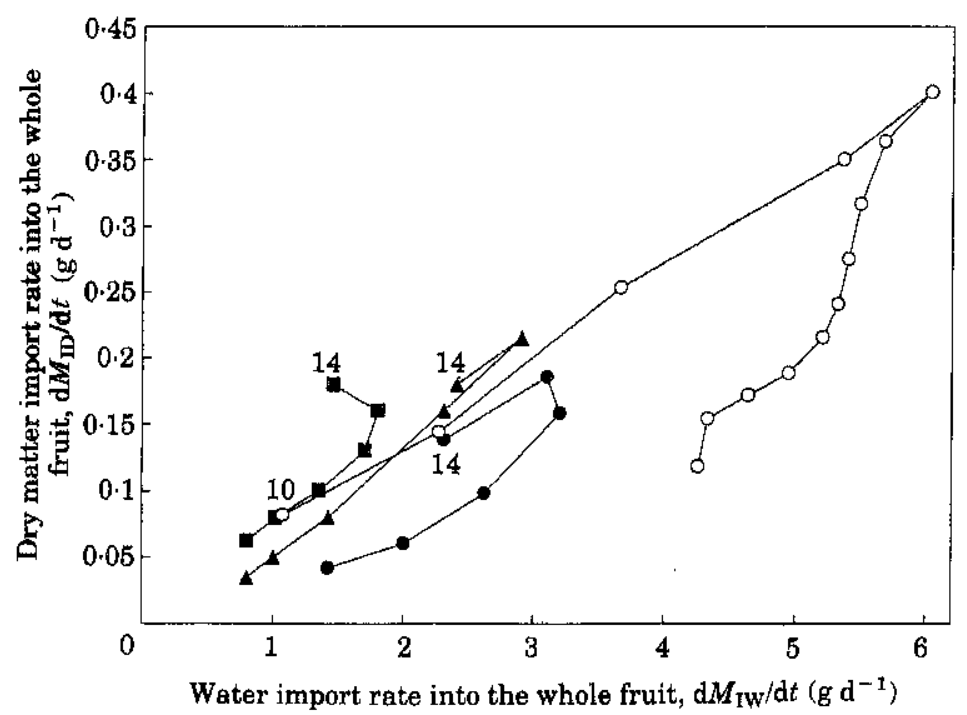

FIG. 8. Dry matter import rate into fruit in relation to the water import rate into fruit. Trial $\mathrm{H}(\mathrm{O})$, trials $\mathrm{S}$ at $2(0$

$12(\mathbf{A})$ or $17(\mathbb{D}) \mathrm{mS} \mathrm{cm}^{-1}$.

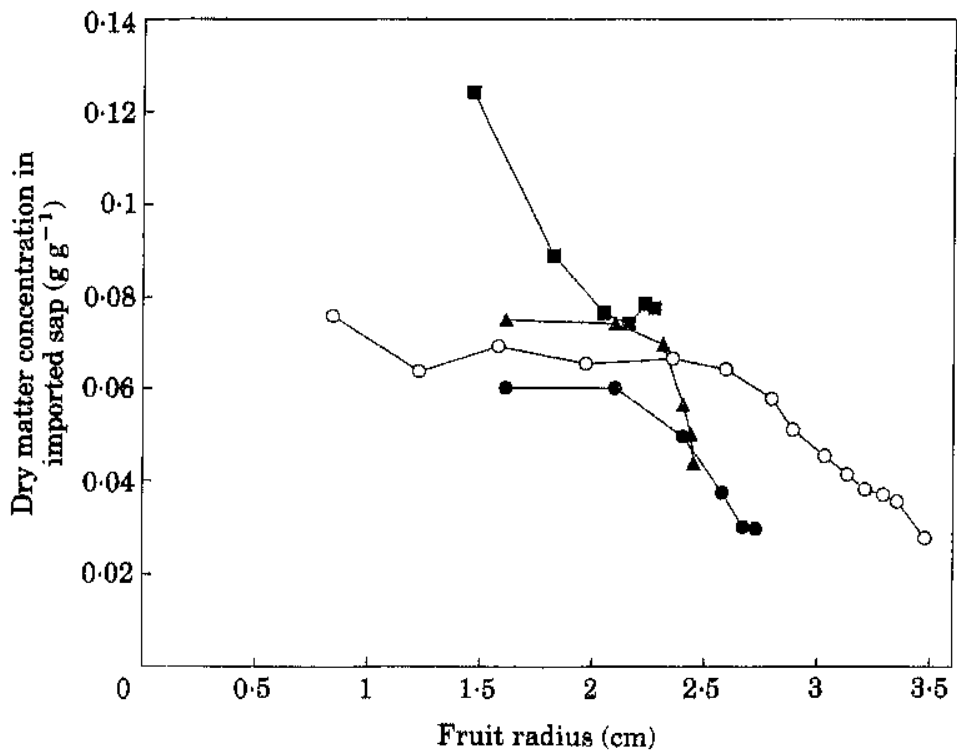

FIG. 9. Change in the dry matter concentration in the imported sap as a function of fruit radius. Trial $\mathrm{H}(\mathrm{O})$, trials $\mathrm{S}$ at $2(\mathbf{O}), 12(\mathbf{A})$ or $17(\mathbf{B}$ $\mathrm{mS} \mathrm{cm}{ }^{-1}$.

of water import $\left(\mathrm{d} M_{\mathrm{IW}} / \mathrm{d} t\right)$ and the dry matter import rate $\left(\mathrm{d} M_{\mathrm{ID}} / \mathrm{d} t\right)$ into the whole fruit (Fig. 8).

\section{Relationship between fruit radius and dry matter concentration of imported sap (Fig. 9)}

In trials other than the one at the greatest salinity, the ratio $F_{\mathrm{ID}} / F_{\mathrm{IW}}$, corresponding to the dry matter concentration in the imported sap, was first constant then decreased as $R$ increased. In the trial at the greatest salinity, it was greater but decreased almost immediately.

Relationship between dry matter concentration of imported sap and radial mean rate due to water import by unit radius (Fig. 10)

Except in the trial at the greatest salinity, dry matter concentration increased first, almost linearly with $F_{\mathrm{IW}} / R$; the dry matter concentration was greater when salinity was high, and the curves were similar in the series $\mathrm{H}$ and in the trial $\mathrm{S}$ at the lowest salinity. Above a value of $F_{\mathrm{IW}} / R$ of approximately $0.03 \mathrm{~g} \mathrm{~cm}^{-8} \mathrm{~d}^{-1}$, the dry matter concentration was constant and similar for the different trials. In the trial at the greatest salinity, the dry matter concentration was constant when $F_{\mathrm{IW}} / R$ was low and similar to that for the other trials when $F_{\mathrm{IW}} / R$ was high; it then increased as $F_{\mathrm{IW}} / R$ increased.

\section{DISCUSSION}

The change in $\sigma_{\mathrm{F}}$ observed during tomato fruit swelling was $\pm 2 \%$, thus the error in $F_{\mathrm{IW}}, F_{\mathrm{IXW}}$ and $F_{\mathrm{ID}}$ in assuming $\sigma_{\mathrm{F}}$ to be constant, was probably lower than $\pm 1.5 \%$ [see eqn (25)], which was negligible compared to the changes of $F_{\mathrm{IW}}$, $F_{\mathrm{IXW}}$ and $F_{\mathrm{ID}}$. The error in the mean value $(0.95)$ of $\sigma_{\mathrm{F}}$ was probably low; assuming an arbitrary error equal to $\pm 10 \%$, 


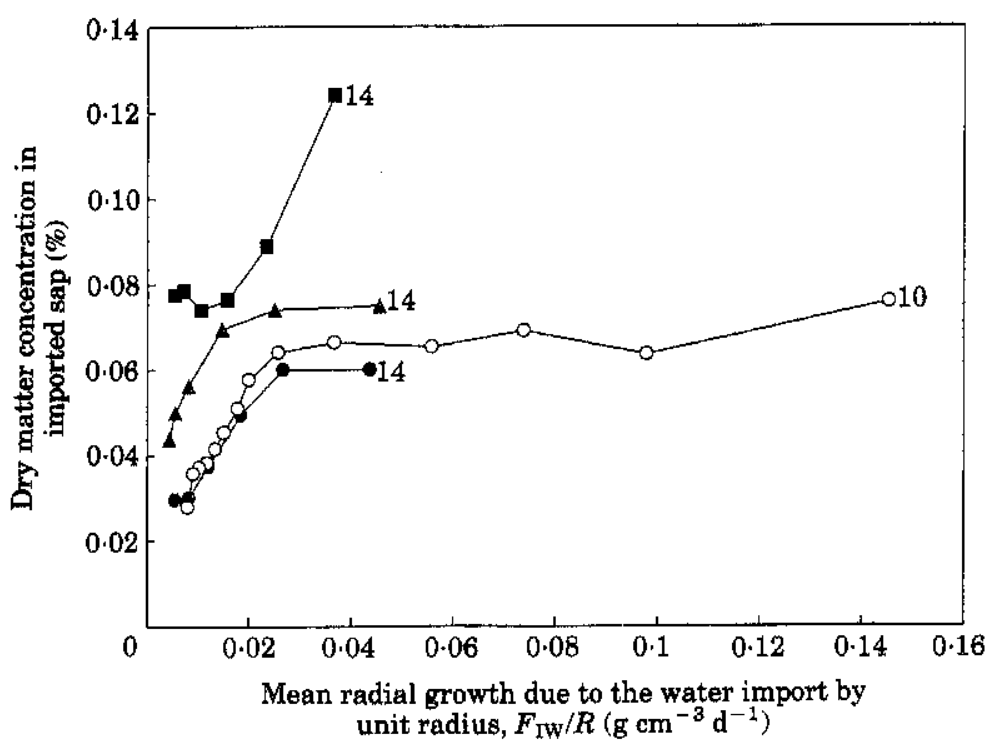

FIG. 10. Change in the dry matter concentration in the imported sap in relation to the fruit radial growth rate due to water import by unit radius $\left(F_{\mathrm{IW}} / R\right)$. Trial $\mathrm{H}(\mathrm{O})$, trials $\mathrm{S}$ at $2(\boldsymbol{O}), 12(\boldsymbol{\Delta})$ or $17(\boldsymbol{Q}) \mathrm{mS} \mathrm{cm}^{-1}$.

the errors in the values of $F_{\mathrm{IW}}, F_{\mathrm{IX} w}$ and $F_{\mathrm{ID}}$ were equal to $\pm 7 \%$

In the trial at the greatest salinity, there was an obvious small error in estimation of data (Table 1), because, according to Ho et al. (1987), the average of the two last values of imported dry matter concentration was slightly lower than the average of the two previous values. Hence, the concentration at the end of the trial continued to decrease slightly rather than increasing, as Figs 9 and 10 suggested. These estimation errors were probably negligible for other results.

It is known that the tomato fruit shows small daily contractions in comparison to other fruits (Ehret and Ho, 1986; Ho et al., 1987; Huguet, pers. comm.; Lee et al., 1989); it is thus reasonable to suppose that the water output rate from fruit towards the remainder of the plant is small.

The greatest rate of water import into the whole fruit $\left(\mathrm{d} M_{\mathrm{IW}} / \mathrm{d} t\right)$ was observed in the first phase of growth in trial $\mathrm{S}$ and in the second phase in trial $\mathrm{H}$. Slightly before, or very quickly after, the greatest rate of water import into the whole fruit, $F_{\mathrm{IW}}$ decreased more quickly and linearly with respect to increasing fruit radius. It is believed that in the first phase, the rate was mainly controlled by the vascular cross-section in the fruit pedicel. This would be consistent with the linear regressions between the area of the vascular tissue in the pedicel and the fruit weight found in small tomato fruits (Starck et al., 1990) and with the existence of the 3-week period of increase in the vascular tissue of the fruit pedicel (Lee, 1990). It is thought that in the second phase the rate was mainly controlled by the resistances in the transfer pathways. At the beginning of second phase in series $\boldsymbol{H}$, there was probably a longer period with effects due to both increase in vascular cross-section and increases in resistances in the transfer pathways. These results could provide an interpretation for the deviations over time observed by Lee (1989) between fruit size modelled using a constant water import and observed fruit size.
The greatest rate of xylem water import into the whole fruit ( $\left.\mathrm{d} M_{\mathrm{Ixw}} / \mathrm{d} t\right)$, was observed at smaller radii than in the case of $F_{\mathrm{IW}}$. This could indicate that $F_{\mathrm{IXW}}$ was more sensitive to the transfer resistances than $F_{\text {IW }}$.

The observed changes in $F_{\mathrm{ID}}$ with respect to $R$ were coherent and suggested that $F_{\mathrm{ID}}$ was controlled by radius and by salinity. $F_{\text {ID }}$ was evidently the product of $F_{\text {IW }}$ and of concentration. The mean rate $F_{\mathrm{TW}} / R$ of radial growth due to water import per unit radius could be seen as an index of the mean turbulence in the transfer pathways. In trials $\mathrm{H}$ and $\mathrm{S}$ at low and mean salinity, the imported dry matter concentration increased with $F_{\text {IW }} / R$ up to about $0.03 \mathrm{~g}$ $\mathrm{cm}^{-3} \mathrm{~d}^{-1}$ (Fig. 10) which coincided approximately with the beginning of the second phase in which $F_{\text {IW }}$ was controlled by the transfer resistances. In this second phase, the concentration decreased when $R$ increased (Fig. 9). In the $\mathrm{H}$ and $\mathrm{S}$ trials at lower salinity, the concentration varied in like manner with $F_{\text {Iw }} / R$ though $R$ was different. These observations could indicate that the imported dry matter concentration was controlled, in this second phase, by a transfer rate which was probably dependent on the turbulence in the transfer pathways. Walker and Ho (1976, $1977 a, b$ ) have shown that the sucrose import rate depends on the gradient of sucrose concentration between plant and fruit and on the sucrose hydrolysis rate. These results suggested that the gradient of sucrose concentration and the sucrose hydrolysis rate could depend on the turbulence in the transfer pathways.

At a given $F_{\mathrm{IW}} / R$, the imported dry matter concentration was higher when salinity was greater. In trial $S$ at the greatest salinity, $F_{\mathrm{ID}}$ and the imported dry matter concentration were much higher at the beginning, the concentration then decreased to the limit value observed in other trials when $F_{\mathrm{IW}} / R$ was lower and $R$ greater. Ho and Baker (1982) reported the importance of $\mathrm{K}^{+}$in sucrose hydrolysis mechanisms. They also indicated that the ratelimiting step of sucrose hydrolysis may be different according 
to conditions. Since in trial S salinity was chiefly increased by the addition of $\mathrm{K}^{+}$, the observed changes might suggest that sucrose hydrolysis rate was controlled by salinity. But, in trial $\mathrm{S}$ the rate-limiting step was probably not the same. The observed regression between $F_{\mathrm{ID}}$ and $R$ in the trial $\mathrm{S}$ at the greatest salinity suggested that the reaction was controlled by a transfer rate dependent on fruit radius.

When the imported dry matter concentration and $F_{\mathrm{ID}}$ seemed to be controlled by the turbulence in the transfer pathways, there could be a dry matter output from the fruit towards the remainder of the plant. Indeed, except at the trial beginning at the greatest salinity, the linear regressions between $F_{\mathrm{ID}}$ and $F_{\mathrm{IW}}$ could indicate that $F_{\mathrm{ID}}$ was the result of a dry matter influx from 'mass-flow' reduced by a value $b$ which was nearly constant during swelling, and much greater at lower salinity. $F_{\mathrm{IW}}$ appeared to be the sum of the radial growth rate due to phloem water influx $\left(F_{\mathrm{FPW}}\right)$ and of the radial growth rate due to xylem water influx $\left(F_{\mathrm{Fxw}}\right)$ reduced by a radial negative growth rate due to a water output $\left(F_{E W W}\right)$ from fruit towards the remainder of the plant:

$$
F_{\text {IW }}=F_{\text {FPW }}+F_{\text {FXW }}-F_{\mathrm{EW}}
$$

When $F_{\mathrm{ID}}$ is the difference between the radial growth rate due to the influx of the dry matter of phloem sap $\left(F_{\mathrm{FPD}}\right)$, and a radial negative growth rate due to a dry matter output $\left(F_{\mathrm{ED}}\right)$ from the fruit towards the remainder of the plant:

$$
F_{\mathrm{ID}}=F_{\mathrm{FPD}}-F_{\mathrm{ED}}
$$

Labelling $\alpha$ as the dry matter concentration of phloem sap which enters fruit $\left(F_{\mathrm{FPD}}=\alpha F_{\mathrm{FPW}}\right)$, then:

$$
\begin{gathered}
F_{\mathrm{ID}}=\alpha\left(F_{\mathrm{IW}}-F_{\mathrm{FXW}}+F_{\mathrm{FW}}\right)-F_{\mathrm{ED}} \\
F_{\mathrm{ID}}=\alpha F_{\mathrm{IW}}-\left(\alpha F_{\mathrm{IXW}}-\alpha F_{\mathrm{EW}}+F_{\mathrm{ED}}\right) .
\end{gathered}
$$

If we suppose that the regression of eqn (26) corresponded to this equation, the coefficient $a$ was equal to $\alpha$ and the coefficient $b$ was equal to the term $\left(\alpha F_{\mathrm{FXW}}-\alpha F_{\mathrm{EW}}+F_{\mathrm{BD}}\right)$ of the previous equation:

$$
b=\alpha F_{\mathrm{FXW}}-\alpha F_{\mathrm{FW}}+F_{\mathrm{ED}}
$$

This equation yielded with $\alpha=a$ :

$$
F_{\mathrm{WD}}=b-a F_{\mathrm{FXW}}+a F_{\mathrm{EW}}
$$

According to this equation, $F_{\mathrm{BD}}$ was necessarily positive if $F_{\text {FXw }}$ was lower than $b / a$. The legend of Fig. 7 indicates the values of $b / a$ obtained in the trials. Assuming that $F_{\mathrm{FXW}}$ was equal to $F_{\mathrm{IXW}}$ (radial growth rate due to the import of water through the xylem), we see (Fig. 5) that $F_{\mathrm{Fxw}}$ was lower than $b / a$, except at the beginning of the trials. Thus $F_{\mathrm{ED}}$ could be positive or equal to zero, except at the beginning of the trials. Since $F_{\mathrm{FXW}}$ decreased linearly when $R$ increased (Fig. 5), and assuming $F_{\mathrm{EW}}$ to be near zero, the $F_{\mathrm{ED}}$ increase with respect to $R$ was also probably linear. This dry matter output could correspond to the carbon export from tomato fruit shown by Walker and Ho $(1976,1977 a, b)$ and Walker, Ho and Baker (1978); these authors found that this export was higher in larger fruits or in cooled fruits and when the sucrose concentration was higher. Since the water import into tomato fruit is greater during the day (Ehret and Ho, 1986), this dry matter output probably took place during the night, when temperature, but also $F_{\mathrm{IW}} / R$ were lower.
Thus the results obtained from data were consistent with the hypothesis that: (a) the water import rate could be controlled during the initial period of fruit swelling mainly by the vascular cross-section of pedicel, and mainly by transfer pathway resistances into fruit during a second period; (b) the water import rate through the xylem could be controlled by the transfer resistances more easily than the water import rate through the phloem, and especially when salinity was high: $(c)$ the dry matter import rate could be controlled, at high salinity, by a transfer rate which might depend on fruit radius; at lower salinity, the dry matter import rate could be controlled by salinity and water import rate. Thus, this work suggested hypotheses, which should be verified and elaborated, and could explain that fruit size itself is a determinant factor of fruit growth.

\section{CONCLUSION}

The published results of Ho et al. $(1987,1983)$ obtained at different salinities with two tomato varieties were used to derive simple relationships between fruit radius and radial growth rate due to water import or dry matter import or their ratio. Some relationships were linear over a long period of tomato fruit growth.

The results suggested that fruit radius was an important parameter of mechanisms on which depend water and dry matter import rates per unit surface area of tomato fruit. It is traditionally thought according to the logistic law that fruit is a 'sink' whose 'strength' is the product of its mass multiplied by sink activity per unit mass. Since the surface area of fruit is directly dependent on the radius, these results suggest that it is more advisable to consider the strength of this sink as being proportional to the product of fruit surface area multiplied by sink activity as a function of the fruit radius, as in eqns (9) and (12).

The results could be used to model assimilate distribution in plants and plant growth (Bussières, 1990; Bussières and Dumas, 1992). They could be also used as the basis of the control of the fruit growth on the potential growth rate estimated by measuring fruit radius for example with micrometric sensors (Huguet, 1985). Moreover, these results could be used to examine fruits other than the tomato and, if necessary, an equation similar to eqn (9) could be used for an elliptic mass.

\section{ACKNOWLEDGEMENTS}

We thank Y. Dumas (INRA, Montfavet) and the reviewers and editors for their counsel and also, persons responsible for EEC Contrat $n^{\circ}$ 8001-CT-91-0305 entitled 'Program of improvement of technological quality of processing tomatoes in the Mediterranean countries' which benefitted this work.

\section{LITERATURE CITED}

Bussières P. 1990. Canevas de modèle d'une ligne de plantes de tomate semées explicitant sa variabilité spatiale. Actae Horticulturae 277: 221-227.

Bussières P, Dumas Y. 1992. An analysis scheme for modeling the functioning of a tomato crop. Actae Horticulturae 301: 171-176. Dempsey WH, Boynton JE. 1965. Effects of seed number on tomato 
fruit size and maturity. Proceedings of the American Society for Horticultural Science 86: 575-581.

Dumas Y, Bussières P. 1992. Mécanisation et réduction des intrants en culture de tomate d'industrie: aspects agronomiques. Pépinièristes, Horticulteurs, Maraîchers-Revue Horticole 324: 55-67.

Ehret DL, Ho LC. 1986. Effects of osmotic potential in nutrient solution on diurnal growth of tomato fruit. Journal of Experimental Botany 37: 1294-1302.

Gustafson FG. 1926. Growth studies on fruits. Plant Physiology 1: $265-272$.

Gustafson FG. 1927. Growth studies on fruits: an explanation of the shape of growth curve. Plant Physiology 2: 153-161.

Ho LC, Baker DA. 1982. Regulation of loading and unloading in long distance transport systems. Physiologia Plantarum 56: 225-230.

Ho LC, Grange RI, Picken AJ. 1987. An analysis of the accumulation of water and dry matter in tomato fruit. Plant, Cell and Environment 10: $157-162$.

Ho LC, Hewitt JD. 1986. Fruit development. In: Atherton JG, Rudlich J, eds. The tomato crop. London: Chapman and Hall, 201-239.

Ho LC, Sjut V, Hoad GV. 1983. The effects of assimilate supply on fruit growth and hormone levels in tomato plants. Plant Growth Regulation 1: 155-171.

Huguet JG. 1985. Appréciation de l'état hydrique d'une plante à partir des variations micrométriques de la dimension des fruits ou des tiges au cours de la journée. Agronomie 5: 733-741.

Hurd RG, Gay AP, Mountifield AC. 1979. The effect of partial removal on the relation between root, shoot and fruit growth in the indeterminate tomato. Annals of Applied Biology 93: 77-89.

Jahn OL. 1978. Fruiting and twig diameter in citrus. American Journal of Botany 65: 1032-1034.

Lai R, Wooley DJ, Lawes GS. 1990. The effect of inter-fruit competition, type of fruiting lateral and time of anthesis on the fruit growth of kiwifruit (Actinidia deliciosa). Journal of Horticultural Science 65: $87-96$.

Lee DR. 1989. Vascularization of the abscission zone of tomato fruit: implications for transport. Canadian Journal of Botany 67: $1898-1902$.

Lee DR. 1990. An unidirectional water flux model of fruit growth. Canadian Journal of Botany 68: 1286-1290.

Lee DR, Dixon MA, Johnson RW. 1989. Simultaneous measurements of tomato fruit and stem water potentials using in situ stem hygrometers. Canadian Journal of Botany 67: 2352-2355.

Maisonneuye B, Philouze J. 1982. Action des basses températures nocturnes sur une collection variétale de tomate (Lycopersicon esculentum). I Etude de la production des fruits et la valeur fécondante du pollen. Agronomie 2: 443-452.

Philouze J. 1983. Parthénocarpie naturelle chez la tomate. I. Revue bibliographique. Agronomie 3: 611-620.

Robertson TB, 1908. On the normal rate of growth of an individual and its biochemical significance. Archiv für Entwicklungsmechanik Organismen 25: 581-614.

Starck Z, Wazynska Z, Kucewicz O, Witek-Czuprynska B. 1990. Relationships between fruit growth and anatomical structure of pedicels in tomato plants treated with growth regulators. Acta Physiologiae Plantarum 12: 59-66.

Walker AJ, Ho LC. 1976. Young tomato fruits induced to export carbon by cooling. Nature 261: 410-411.

Walker AJ, Ho LC. 1977a. Carbon translocation in the tomato: carbon import and fruit growth. Annals of Botany 41: 813-823.

Walker AJ, Ho LC. 1977b. Carbon transiocation in the tomato: effects of fruit temperature on carbon metabolism and the rate of translocation. Annals of Botany 41 : 825-832.

Walker AJ, Ho LC, Baker DA. 1978. Carbon translocation in the

tomato: pathways of carbon metabolism in the fruit. Annals of Botany 42: 901-909.

Walker AJ, Thornley JHM. 1977. The tomato fruit: import, growth, respiration and carbon metabolism at different fruit sizes and temperatures. Annals of Botany 41: 977-985.

$a$

$b\left(\mathrm{~g} \mathrm{~cm}^{-2} \mathrm{~d}^{-1}\right)$

$\alpha$

$C W$

$F$

$F_{\mathrm{ID}}\left(\mathrm{g} \mathrm{cm}^{-2} \mathrm{~d}^{-1}\right)$

$F_{\text {EW }}\left(\mathrm{g} \mathrm{cm}^{-2} \mathrm{~d}^{-1}\right)$

$F_{\text {FPD }}\left(\mathrm{g} \mathrm{cm}^{-2} \mathrm{~d}^{-1}\right)$

$F_{\text {FPW }}\left(\mathrm{g} \mathrm{cm}^{-2} \mathrm{~d}^{-1}\right)$

$F_{\text {FXW }}\left(\mathrm{g} \mathrm{cm}^{-2} \mathrm{~d}^{-1}\right)$

$F_{\text {ID }}\left(\mathrm{g} \mathrm{cm}^{-2} \mathrm{~d}^{-1}\right)$

$F_{\text {IW }}\left(\mathrm{g} \mathrm{cm}^{-2} \mathrm{~d}^{-1}\right)$

$F_{\text {IXW }}\left(\mathrm{g} \mathrm{cm}^{-2} \mathrm{~d}^{-1}\right)$

$M_{\text {AD }}(\mathrm{g})$

$M_{\text {Aw }}(\mathrm{g})$

$M_{\text {ID }}(\mathrm{g})$

$M_{\text {IW }}(\mathrm{g})$

$M_{\mathrm{F}}(\mathrm{g})$

$M_{\mathrm{RD}}(\mathrm{g})$

$M_{\text {LW }}(\mathrm{g})$

$R(\mathrm{~cm})$

$\sigma_{\mathrm{F}^{*}}\left(\mathrm{~g} \mathrm{~cm}^{-3}\right)$

$\sigma_{\text {ID }}\left(\mathrm{g} \mathrm{cm}^{-3}\right)$

$\sigma_{\mathrm{W}}\left(\mathrm{g} \mathrm{cm}^{-3}\right)$

$t$ (d)

$T_{\mathrm{ADF}}(\%)$

$V\left(\mathrm{~cm}^{-3}\right)$

Rate of change:

$M_{\mathrm{AD}}: \quad \mathrm{d} M_{\mathrm{AD}} / \mathrm{d} t$

$M_{\mathrm{AW}}^{\mathrm{AD}}: \quad \mathrm{d} M_{\mathrm{AW}} / \mathrm{d} t$

$M_{\mathrm{F}}: \quad \mathrm{d} M_{\mathrm{F}} / \mathrm{d} t$

$M_{\mathrm{ID}}: \quad \mathrm{d} M_{\mathrm{ID}} / \mathrm{d} t$

$M_{\mathrm{TW}}: \quad \mathrm{d} M_{\mathrm{IW}} / \mathrm{d} t$

$M_{\mathrm{RD}}: \quad \mathrm{d} M_{\mathrm{RD}} / \mathrm{d} t$

$M_{\mathrm{RW}}: \mathrm{d} M_{\mathrm{RW}} / \mathrm{d} t$

$M_{\mathrm{T} W} \mathrm{~d} M_{\mathrm{TW}} / \mathrm{d} t$

$R: \quad \mathrm{d} R / \mathrm{d} t$

\section{APPENDIX}

Regression coefficient of $F_{\mathrm{ID}}$ in respect to $F_{\text {IW }}$

Constant term of regression of $F_{\mathrm{ID}}$ in respect to $F_{1 W}$

Dry matter content of the phloem water

Ratio of $\mathrm{d} M_{\mathrm{RW}} / \mathrm{d} t$ to $\mathrm{d} M_{\mathrm{RD}} / \mathrm{d} t$

Radial growth (or negative growth) rate due to:

Dry matter output from the fruit towards the remainder of the plant

Water output from the fruit towards the remainder of the plant

Phloem dry matter influx in the fruit

Phloem water influx in the fruit

Xylem water influx in the fruit

Dry matter import in the fruit

Water import in the fruit

Xylemic water import in the fruit

Dry matter mass accumulated in the fruit

Water mass accumulated in the fruit

Dry matter mass imported in the fruit

Water mass imported in the fruit

Fruit mass

Dry matter mass loss through respiration

Water mass produced by dry matter loss through respiration

Fruit radius

Fruit density

Imported dry matter density

Water density

Time

Fruit dry matter content

Fruit volume

( $\mathrm{g} \mathrm{d}^{-1}$ per fruit)

( $\mathrm{g} \mathrm{d}^{-1}$ per fruit)

( $\mathrm{g} \mathrm{d}^{-1}$ per fruit)

( $\mathrm{g} \mathrm{d}^{-1}$ per fruit)

( $\mathrm{g} \mathrm{d}^{-1}$ per fruit)

( $\mathrm{g} \mathrm{d}^{-1}$ per fruit)

( $\mathrm{g} \mathrm{d}^{-1}$ per fruit)

( $\mathrm{g} \mathrm{d}^{-1}$ per fruit)

$\left(\mathrm{cm} \mathrm{d}^{-1}\right)$. 